\title{
Serebral Kavernomların Manyetik Rezonans Görüntüleme Bulguları
}

\author{
Magnetic Resonance Imaging Findings of Cerebral Cavernomas \\ Erkan Gökçe ${ }^{1}$, Murat Beyhan ${ }^{2}$, Berat Acu ${ }^{3}$, Fatma Aktaş${ }^{1}$, Zafer Özmen ${ }^{1}$ \\ 'Gaziosmanpaşa Üniversitesi, Tıp Fakültesi, Radyoloji Anabilim Dalı, Tokat \\ ${ }^{2}$ Tokat Devlet Hastanesi, Radyoloji Ünitesi, Tokat \\ ${ }^{3}$ Osmangazi Üniversitesi, Tıp Fakültesi, Radyoloji Anabilim Dalı, Eskişehir
}

\begin{abstract}
öz
Amaç: Serebral kavernomlar, arasında normal beyin parankimi olmayan anormal genişlemiş kapiller kavitelerle karakterize vasküler malformasyonlardır. Bu çalışmada serebral kavernomların manyetik rezonans görüntüleme (MRG) bulguları sunulmaktadır.

Gereç ve Yöntem: Çalışmaya çeşitli nörolojik şikayetler nedeniyle beyin MRG tetkiki uygulanan ve tetkiklerinde kavernom saptanan, 19'u kadın, 17'si erkek toplam 36 hasta dahil edildi. MRG'de kavernomların tipleri, yerleşim alanları, volümleri, T2A serilerde hemosiderin halkalarının varlığı ve şekli, eşlik eden gelişimsel venöz anomali (GVA) varlığı, kontrastlı serilerde kontrastlanma paternleri araştırıldı. Kavernomların volümleri ile kontrastlanma arasındaki ilişki araştırıldı.
\end{abstract}

Bulgular: Otuzaltı kavernomun 17'si kortikal-subkortikal, 11 'i derin, 5'i subkortikal-santral beyaz cevher, üçü santral beyaz cevherde yerleşimliydi. Kavernomların hacimleri 0,02-6,50 ml (ortanca 0,45 ml) arasında değişmekteydi. Kavernomların 19'unda kesintili, 15'inde kesintisiz hemosiderin halkası varken ikisinde saptanamadı. Kavernomların 23'ü keskin, 11'nispeten düzgün konturlu iken ikisi belirsiz sınırlı olup bunların şekil itibariyle 24'ü lobule, 11'i yuvarlak, biri şekilsizdi. Zabramski sınıflamasına göre kavernomların 22'si Tip 2, 13'ü Tip 1 ve biri de Tip 3'tü. Kavernomların 14'ünde kontrastlanma saptanmazken, 7'sinde progresif, üçünde fokal-punktat, üçünde periferal, birinde ise difüz kontrastlanma görüldü. Kavernom volümleri ile kontrastlanma arasında istatistiki olarak anlamlı ilişki saptanmadı ( $p=0,382)$. Hastaların 18'inde kavernoma GVA eşlik etmekteydi.

Sonuç: Kavernomlar sıklıkla GVA'nın eşlik ettiği, içerisindeki kanama ürünlerinin miktarı ve evresine göre değişken MR görünüm özellikleri sergileyen, volümden bağımsız farklı kontrastlanma paternleri içeren vasküler orjinli lezyonlardır.

Anahtar Kelimeler: Kavernöz anjiom; manyetik rezonans görüntüleme; santral sinir sistemi venöz anjioma.

\section{ABSTRACT}

Objective: Cerebral cavernomas are vascular malformations characterized by abnormally enlarged capillary cavities with abnormal brain parenchyma. In present study, magnetic resonance imaging (MRI) findings of cerebral cavernomas are presented.

Material and Methods: Nineteen female and 17 male patients, who had brain MRI examination due to various complaints and found to have cavernoma were included. Cavernomas types, location, volumes, hemosiderin rings and shape, accompanying DVA and contrast enhancement were investigated in MRI. Association between cavernoma volumes and contrast enhancement was investigated.

Results: Of 36 cavernomas, 17 were in cortical-subcortical area, 11 in deep, 5 in subcortical-central white matter, and 3 in central white matter. The cavernoma volume range was $0.02-6.50 \mathrm{ml}$ (median 0,45 ml). Nineteen of them had discontinuous hemosiderin rings and 15 continuous ones, while two had none. Whereas 23 of them had sharp contour and 11 had relatively straight contour, 2 were indefinitely bordered. Twenty-four were lobule in shape, 11 was round and 1 was formless. Twenty-two of the cavernomas were of type 2, 13 type 1, and 1 type 3. While there were not contrast enhancement in 14 of cavernomas, progressive enhancement was observed in 7 , focal-punctate in 3, peripheral in 3 and diffuse contrast enhancement in 1. Contrast enhancement was not significantly associated with cavernoma volumes ( $p=0,382)$. In 18 patients, cavernoma was accompanied by DVA.

Conclusion: Cavernomas are lesions of vascular origin frequently accompanied by DVA, showing changeable MRI characteristics with volume-independent contrast enhancement patterns according to amount and stage of bleeding products within them.

Keywords: Cavernous angioma; magnetic resonance imaging; central nervous system venous angioma. 


\section{GíRiş}

Kavernomlar, gelişimsel venöz anomali (GVA), arteriyovenöz malformasyon (AVM) ve kapiller telenjiyektazi ile birlikte santral sinir sistemi (SSS)'nin 4 ana tip vasküler malformasyonlarından birini oluştururlar (1). Serebral kavernomlar, arasında normal beyin parankimi olmayan anormal genişlemiş kapiller kavitelerle karakterize hamartomatöz vasküler malformasyonlardır (1-3). Kavernomların otopsi serilerinde görülme sıklığı yaklaşık \% 0,5, manyetik rezonans görüntüleme (MRG)'de ise yaklaşık \% 0,7'dir (1, $2,4)$. Kavernomlar sıklıkla asemptomatik lezyonlar olup genellikle başka bir nedenle yapılan beyin görüntülemelerinde insidental olarak saptanırlar ancak, baş ağrısı, epileptik nöbet ve inme benzeri semptomlara da yol açabilirler (1). Kavernomlar gelişimleri boyunca değişebilen dinamik lezyonlar olduğundan dolayı radyolojik görüntüleme bulguları da değişkenlik gösterebilir (1). Bu çalışmada serebral kavernomların MRG bulguları sunulmaktadır.

\section{GEREÇ ve YÖNTEM}

Çalışmaya Ekim 2008 - Mart 2014 tarihleri arasında baş ağrısı, vertigo, epilepsi, inme gibi çeşitli şikayetleri nedeniyle beyin MRG tetkiki uygulanan ve bu tetkiklerinde kavernom saptanan 19'u kadın, 17'si erkek toplam 36 hasta dahil edildi. Hastaların görüntüleri retrospektif olarak Radyoloji Anabilim Dalımız'da bulunan PACS sistemi (GE Healthcare, Milwaukee, WI, USA) üzerinden değerlendirildi. MRG tetkikleri 1.5 Tesla (T) MR cihazında (Signa excite HD; GE Healthcare, Milwaukee, WI, USA) 8 kanallı nörovasküler-kafa koili kullanılarak yapıldı. Konvansiyonel MRG sekansları yanında gradiyent T2 ile kontrastlı serilerde spin eko sekanslarla birlikte 3 boyutlu Spoiled Gradient Recalled (3B SPGR) sekansı da alındı. Hastaların 28'ine kontrastlı beyin MRG, 8'ine kontrastsız beyin MRG, 19'una ise MRG öncesi bilgisayarlı tomografi (BT) incelemesi yapılmıştı. MRG'de kavernomların yerleşim alanları (kortikal-subkortikal, subkortikal-santral beyaz cevher, santral beyaz cevher, derin) değerlendirildi. Periventriküler, bazal ganglion, beyin sapı ve dentat nükleusta yerleşen kavernomlar derin yerleşimli olarak kabul edildi. Kavernomların volümleri üç düzlemdeki boyutlarının 0,5 ile çarpılması ile elde olundu. T2 ağırlıklı (T2A) serilerde hemosiderin halkalarının varlığı ve şekli (kesintili-kesintisiz) incelendi. T2A serilerde hemosiderin halkada milimetrik boyutlardaki devamsızlıklar kesinti olarak kabul edildi. Kavernomlara eşlik eden GVA varlığı araştırıldı. Kontrastlı serilerde kavernomların kontrastlanıp kontrastlanmadıkları incelendi. Kontrastlanan kavernomlarında kontrastlanma paternleri (progresif, fokal-punktat, halkasal, difüz) incelendi. Zambramski sınıflamasına göre kavernomların tipleri değerlendirildi (3). BT'de akut-subakut hemoraji ve kalsifikasyon içerip içermediklerine bakıldı. Kavernomların volümleri ile kontrastlanma arasında ilişki olup olmadığı Mann-Whitney U testi ile değerlendirildi. P değeri 0,05'in altı anlamlı kabul edildi.

\section{BULGULAR}

Beyin MRG tetkiklerinde kavernom saptanan

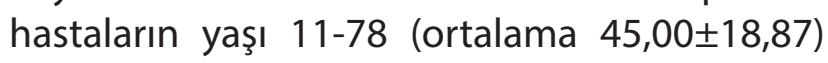
arasında değişmekteydi. Saptanan 36 kavernomun 17'si kortikal-subkortikal, 11'i derin, 5'i subkortikal-santral beyaz cevher, üçü santral beyaz cevher alanlarında yerleşim göstermekteydi. Kavernomların hacimleri 0,02-6,50 ml (ortanca $0,45 \mathrm{ml}$ ) arasında değişmekteydi. Kavernomların 19'unda kesintili, 15'inde kesintisiz hemosiderin halkası varken ikisinde hemosiderin halkası saptanamadı. Kavernomların 23'ü keskin, 11 'nispeten düzgün konturlu iken ikisi belirsiz sınırlı olup bunların şekil itibariyle 24'ü lobule, 11'i yuvarlak, biri şekilsizdi. Zabramski sınıflamasına göre kavernomların 22'si Tip 2 (Şekil I ve II), 13'ü Tip 1 (Şekil III) ve biri de Tip 3 (Şekil IV) iken Tip 4 kavernom saptanmadı. Kavernomların 14'ünde kontrastlanma saptanmazken (Şekil IV), 7'sinde yama tarzı geç serilerde gittikçe artan (Şekil I), üçünde fokal-punktat (Şekil II), üçünde periferal, birinde ise difüz kontrastlanma görüldü. Kavernom volümleri ile kontrastlanma arasında istatistiki olarak anlamlı ilişki saptanmadı ( $p=0,382)$. Onsekiz (\% 50) hastada kavernoma eşlik eden GVA saptandı (Şekil III ve V). BT'de kavernomların 11'inde homojen hiperdens, birinde ise sIVI-SIVI seviyelenmesi gösteren (Resim 5) ve birinde de heterojen hiperdens kanama görülürken, 6'sında punktat ya da fokal kalsifikasyonlar saptandı (Şekil II). 


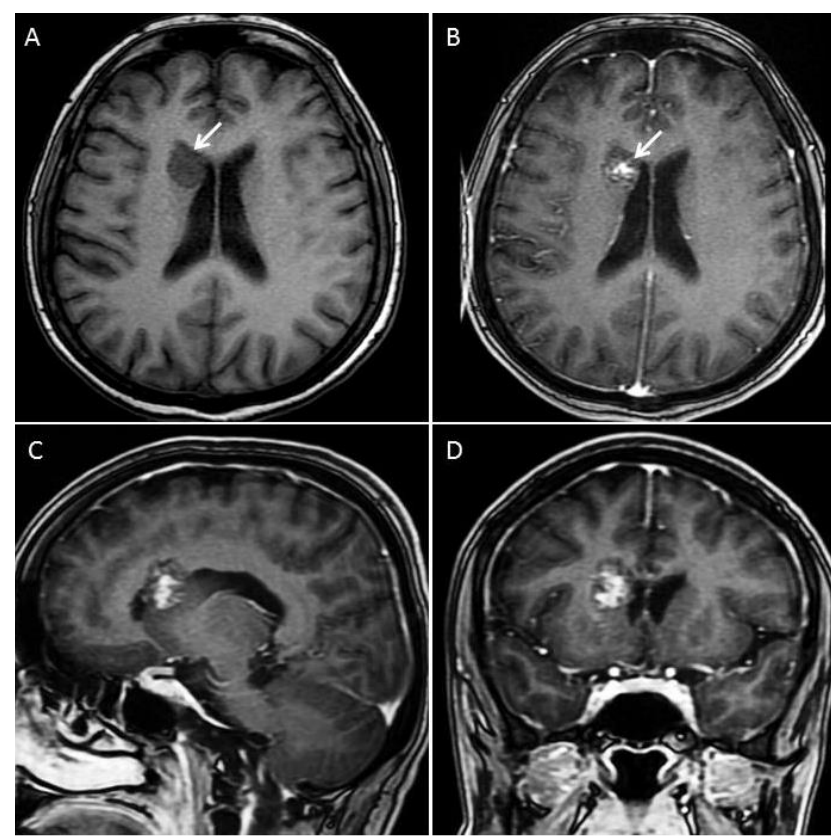

Şekil I: Takipte kavernom tanılı 58 yaşında kadın hasta A) Aksiyel SPGR MRG'de sağda kaudat nükleusta yerleşmiş hipointens Tip 2 kavernom B) Kontrastlı aksiyel SPGR MRG'de kavernom santralinde fokal-punktat kontrastlanmanın başladığı görülmekte C) Ardışık kontrastlı sagittal ve D) kontrastlı koronal SPGR MRG'de kontrastlanmanın perifere doğru artarak devam ettiği görülmektedir.
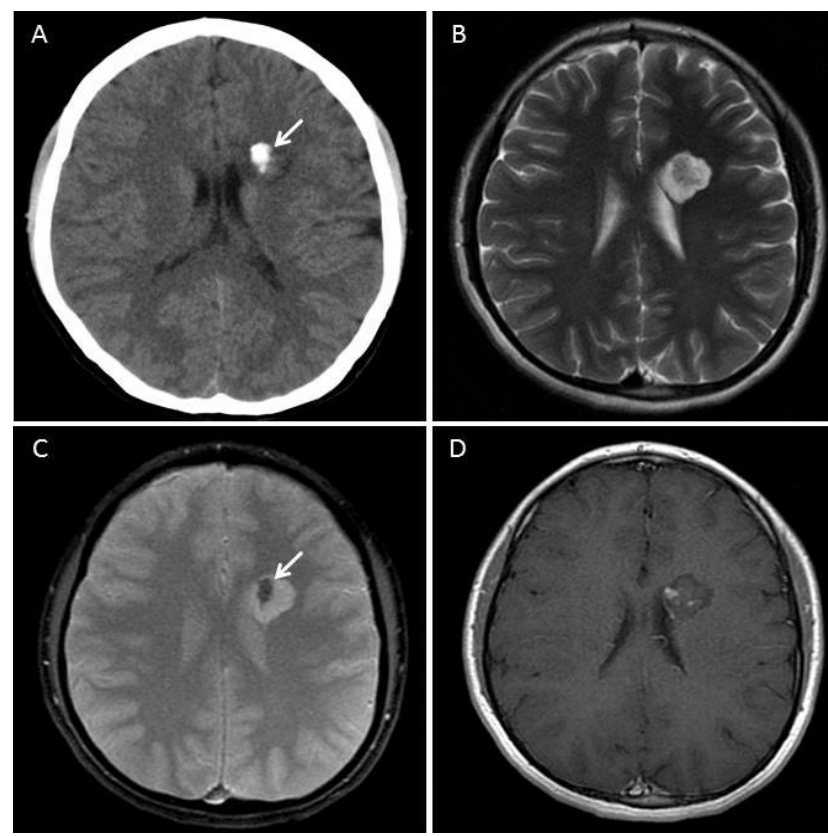

Şekil II: SVH ön tanılı Tip 2 kavernomlu 16 yaşında kadın hasta A) BT'de içerisinde kaba kalsifikasyon bulunan, gri cevhere yakın dansitede, derin yerleşimli kavernom (ok) B) T2A MR'da heterojen hiperintens sinyal kayıtları gösteren, zayıf-ince hemosiderin halkası içeren, lobule konturlu kavernom C) Gradiyent T2A MRG'de kavernom içinde kaba kalsifikasyona ait hipointensite (ok) görülmekte $D$ ) Kontrastlı spin eko T1A MRG'de kavernom içinde fokal-punktat kontrastlanma alanları görülmektedir.
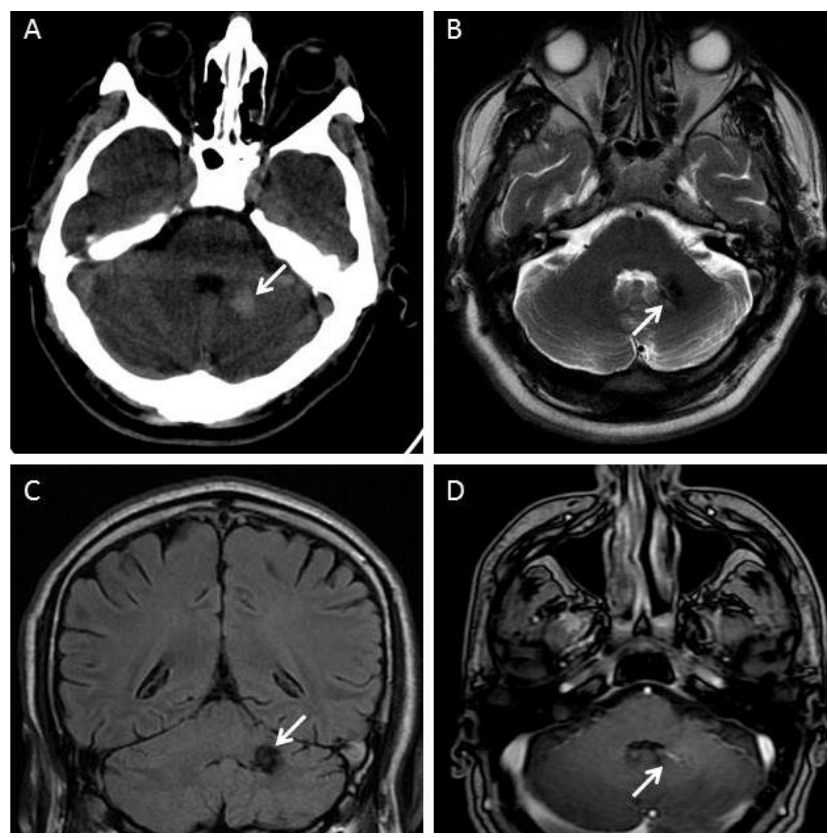

Şekil III: Status epileptikusu olan Tip 1 kavernomlu 31 yaşında kadın hasta A) Beyin BT'sinde sol dentat nükleusta hematom görülmekte B) On gün sonraki aksiyel T2A MRG'de hemoraji nedeninin kavernom olduğu anlaşılmakta. Kavernomun içerisine uzanan küçük GVA'ya ait hiperintensiteler görülmekte C) Koronal flair sekansında GVA seçilememekte D) Aksiyel kontrastlı SPGR sekansında subepandimal venlere drene toplayıcı veni olan küçük GVA görülmektedir.
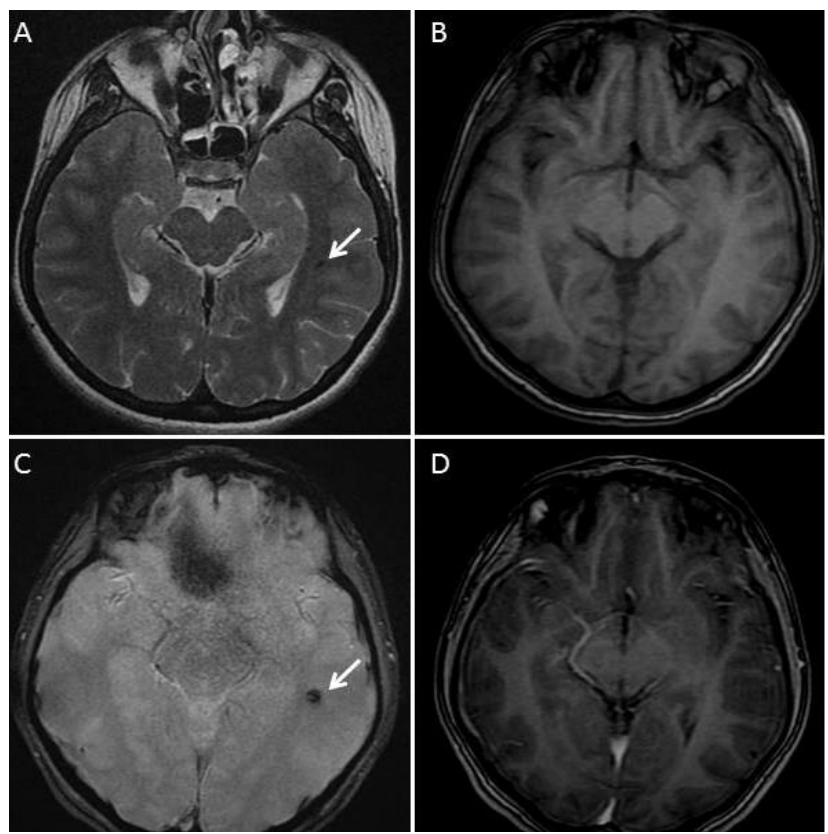

Şekil IV: Epilepsi kliniği ile gelen 16 yaşında Tip 3 kavernomu olan kadın hasta A) T2A MRG'de sol temporal beyaz cevherde milimetrik hipointesite görülmekte (ok) B) SPGR MRG'de lezyon seçilememekte C) Gradiyent T2A MRG'de lezyonun belirgin hemosiderin içeriğine ait hipointensite görülmekte (ok) D) Kontrastlı SPGR MRG'de kavernomda kontrastlanma saptanamamaktadır. 

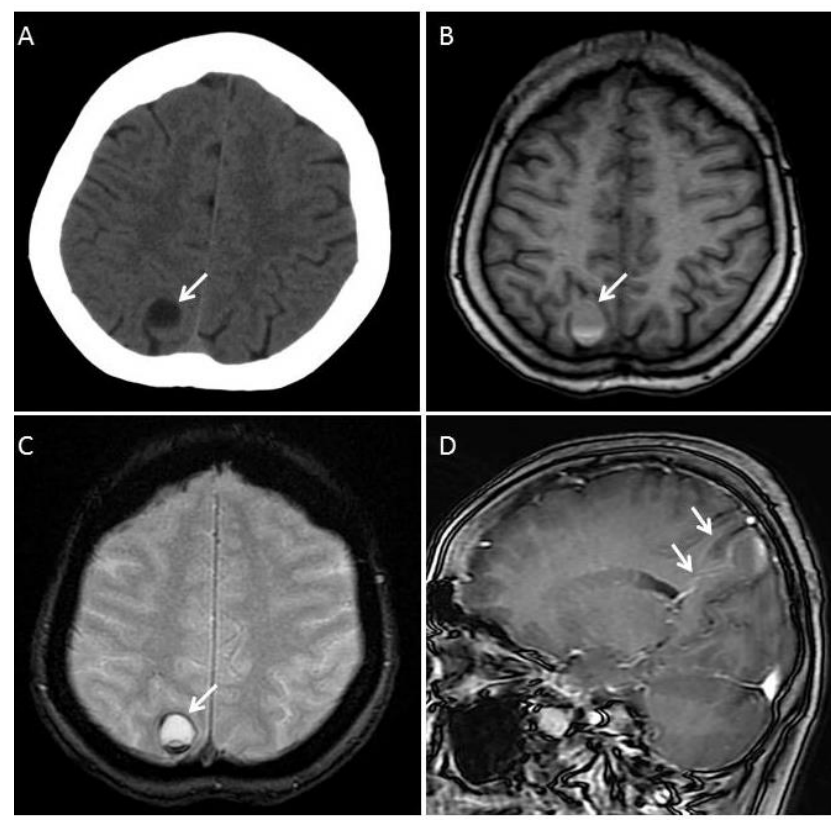

Şekil V: SVH ön tanılı 63 yaşında hasta A) Beyin BT ve B) SPGR MRG'de sağ paryetal lobda içinde kanama ürünlerine ait sIVIsIVı seviyelenmesi gösteren düzgün konturlu kistik kitle (ok) görülmekte C) Gradient T2A MRG'de lezyon etrafında kesintisiz hemosiderin rim (ok) ve içinde kanama ürünlerine ait SIVI-SIVI seviyelenmesi görülmekte D) Kontrastlı SPGR MRG'de kavernom komşuluğuna uzanan GVA'nın kaputu (oklar) görülmektedir.

Tablo I'de hastaların demografik bilgileri, klinik bulguları ile kavernomların yerleşim alanları, volümleri ve Zabramski sınıflamasına göre tipleri sunulmaktadır.

\section{TARTIŞMA}

Kavernomlar GVA ve kapiller telenjiektazilerden sonra üçüncü sıklıkta görülen tüm serebral vasküler malformasyonların \%5-13'ünü oluşturan vasküler malformasyonlardır (1, 3, 5). Her ne kadar kavernomlar ilk tanımlandıklarında nadir lezyonlar olarak kabul edilmiş olsalar da özellikle MRG'nin geliştirilmesinden sonra nöroradyolojik incelemelerde gittikçe artan sıklıkta karşılaşılmaya başlanmıştır (1). Özellikle yüksek Tesla'lı cihazlar (3-9.4 T) ve vasküler yapılar ile kanama odaklarını saptamaya duyarlı gradiyent T2 ve Susceptibility Weighted Imaging (SWI) sekanslarının kullanımının yaygınlaşmasıyla saptanabilirliğinin artacağı düşünülmektedir $(2,6)$. Kavernomların literatürde kavernöz anjiom, kavernöz malformasyon, anjografik olarak okkült vasküler malformasyon şeklinde geniş bir aralıkta isimlendirildiği görülmektedir (1). Literatürde kavernom, kapiller telenjiyektazi ve GVA'nın aynı hastalığın bir spektrumu olduğunu belirten çalışmalar bulunduğu gibi kavernomların GVA'dan geliştiğini belirten yayınlarda bulun-

\begin{tabular}{|c|c|c|c|c|c|c|}
\hline Yaş & Cinsiyet & Klinik & Lokasyon & Yerleşim alanı & $\begin{array}{c}\text { Volüm } \\
\text { (ml) }\end{array}$ & Tip \\
\hline 11 & $\mathrm{E}$ & Epilepsi & sol frontal & Santral & 0.60 & 2 \\
\hline 78 & E & $\begin{array}{c}\text { Ateş, } \\
\text { Baş ağıIsı }\end{array}$ & sağ frontal & Derin & 0.55 & 1 \\
\hline 72 & $\mathrm{E}$ & Unutkanlık & sağ frontal & Kortikal-subkortikal & 0.10 & 2 \\
\hline 36 & $\mathrm{E}$ & Baş ağrısı & $\begin{array}{c}\text { Sağ } \\
\text { temporal }\end{array}$ & Subkortikal-santral & 0.36 & 2 \\
\hline 26 & K & $\begin{array}{c}\text { Şiddetli } \\
\text { baş ağıısı }\end{array}$ & Sol frontal & Subkortikal-santral & 1.01 & 1 \\
\hline 38 & $\mathrm{k}$ & $\begin{array}{c}\text { Distoni, } \\
\text { baş ağıısı }\end{array}$ & Sol frontal & Kortikal-subkortikal & 0.70 & 1 \\
\hline 59 & $\mathrm{E}$ & $\begin{array}{l}\text { Vertigo, } \\
\text { SVH }\end{array}$ & Sol frontal & Subkortikal-santral & 0.04 & 2 \\
\hline 61 & $\mathrm{E}$ & Unutkanlık & $\begin{array}{c}\text { Sol } \\
\text { temporal }\end{array}$ & Kortikal-subkortikal & 0.03 & 2 \\
\hline 29 & $\mathrm{E}$ & Epilepsi & Pons & Derin & 0.14 & 2 \\
\hline 57 & $\mathrm{k}$ & Kontrol & $\begin{array}{c}\text { Sağ } \\
\text { temporal }\end{array}$ & Kortikal-subkortikal & 0.60 & 2 \\
\hline 16 & $\mathrm{k}$ & SVH & $\begin{array}{c}\text { Sol } \\
\text { periventriküler }\end{array}$ & Derin & 4.15 & 2 \\
\hline 32 & $\mathrm{~K}$ & Baş ağrısı & Sol kaudat & Derin & 0.03 & 2 \\
\hline 58 & $\mathrm{~K}$ & Kontrol & Sağ kudat & Derin & 3.36 & 2 \\
\hline 31 & $\mathrm{E}$ & $\begin{array}{c}\text { Baş ağrısı, } \\
\text { epilepsi }\end{array}$ & Sol dentat & Derin & 0.72 & 1 \\
\hline 78 & $\mathrm{E}$ & SVH & Sağ oksipital & Kortikal-subkortikal & 0.67 & 2 \\
\hline 45 & $\mathrm{k}$ & Baş ağrısı & $\begin{array}{c}\text { Medulla } \\
\text { oblangata }\end{array}$ & Derin & 0.02 & 2 \\
\hline 16 & $\mathrm{~K}$ & Epilepsi & Sol temporal & Subkortikal-santral & 0.06 & 3 \\
\hline 51 & $\mathrm{~K}$ & İKK & Sağ temporal & Santral & 0.20 & 2 \\
\hline 53 & $\mathrm{~K}$ & Vertigo & Sol dentat & Derin & 0.09 & 2 \\
\hline 38 & K & Kontrol & Sağ dentat & Derin & 0.36 & 1 \\
\hline 30 & $\mathrm{~K}$ & IKK & Sağ frontal & Kortikal-subkortikal & 1.66 & 2 \\
\hline 63 & $\mathrm{~K}$ & SVH & Sağ paryetal & Kortikal-subkortikal & 1.73 & 1 \\
\hline 46 & $\mathrm{~K}$ & Baş ağrısı & Sağ frontal & Kortikal-subkortikal & 0.19 & 1 \\
\hline 64 & E & İKK & Sol temporal & Kortikal-subkortikal & 1.32 & 1 \\
\hline 44 & $\mathrm{k}$ & Kontrol & Sağ frontal & Kortikal-subkortikal & 1.12 & 2 \\
\hline 68 & $\mathrm{~K}$ & IKK & Sağ frontal & Kortikal-subkortikal & 0.11 & 2 \\
\hline 60 & $\mathrm{E}$ & $\begin{array}{c}\text { Baş ağrısı, } \\
\text { SAK }\end{array}$ & Sol frontal & Kortikal-subkortikal & 0.16 & 1 \\
\hline 25 & $\mathrm{~K}$ & Baş ağıısı & Sağ frontal & Subkortikal-santral & 0.26 & 2 \\
\hline 72 & $\mathrm{E}$ & $\begin{array}{c}\text { SVH, } \\
\text { Demans }\end{array}$ & Sağ frontal & Santral & 0.10 & 2 \\
\hline 23 & $\mathrm{E}$ & Baş ağrısı & Sol oksipital & Kortikal-subkortikal & 0.65 & 1 \\
\hline 57 & $\mathrm{E}$ & $\begin{array}{c}\text { Trigeminal } \\
\text { nevralji }\end{array}$ & Mezensefalon & Derin & 0.09 & 2 \\
\hline 63 & E & Vertigo & Sağ paryetal & Kortikal-subkortikal & 0.11 & 2 \\
\hline 28 & $\mathrm{k}$ & Baş ağrısı & $\begin{array}{c}\text { Sol } \\
\text { frontoparyetal }\end{array}$ & Kortikal-subkortikal & 6.50 & 1 \\
\hline 36 & $\mathrm{E}$ & Epilepsi & Sağ paryetal & Kortikal-subkortikal & 0.86 & 2 \\
\hline 28 & $\mathrm{k}$ & Baş ağıısı & $\begin{array}{c}\text { Sol } \\
\text { periventriküler }\end{array}$ & Derin & 3.78 & 1 \\
\hline 28 & E & Epilepsi & Sağ oksipital & Kortikal-subkortikal & 1.47 & 1 \\
\hline
\end{tabular}

Tablo I: Hastaların demografik özellikleri ve klinik bilgileri ile kavernomların yerleşim alanları, volümleri ve Zabramski sınıflamasına göre tipleri.

SVH: Serebrovasküler hastalık; IKK: İntra kraniyal kitle; SAK: Subaraknoid kanama

maktadır (1, 6-8). GVA'nın bir dalında oklüzyon gelişmesi, radyoterapiye maruz kalması, KRIT1 ya da diğer bilinen mutasyonlar gibi genetik faktörler sonucu GVA'dan kavernom gelişebildiği belirtilmektedir (6). Bizim çalışmamızda takip MRG'leri olan hastalarda GVA'dan gelişen yeni 
bir kavernom saptanmamakla birlikte GVA'ya eşlik eden kavernomların daha öncesine ait tetkikleri olmadığından dolayı hastalarımızda GVA'dan kavernom gelişip gelişmediğine dair net bilgi sağlanamamıştır. Kavernomlar izole ya da multipl olabilirler (9). Sporadik formları olguların \% 50-80'ini oluşturur ve genellikle soliter ya da GVA ile ilişkili lezyonlar şeklinde görülür $(2,3)$. Literatürde sporadik kavernomların \% 14-44'üne GVA'nın eşlik ettiği belirtilmektedir $(6,10)$. Bizim çalışmamızda ise saptanan kavernomların hepsi sporadik formda olup kavernom-GVA birlikteliği \% 50 olarak literatüre göre daha yüksek bulunmuştur. Bunda çalışmamızda hastaların büyük çoğunluğunda (\% 78) kontrastlı incelemenin yapılmış olması ve nispeten gradiyent gücü yüksek cihaz ve 8 kanallı nörovasküler-kafa koili kullanmış olmanın katkısının olduğunu düşünmekteyiz. Kavernomların bir diğer formu olan multipl kavernomlar ise sıklıkla aileseldir ve otozomal dominant geçiş gösterirler (9). Ailesel formlarda CCM1/KRIT 1, CCM2/ MGC 4067 ve CCM3/PDC10 olmak üzere üç gen tanımlanmıştır (2). Bizim çalışmamızda multipl ya da ailesel kavernom saptanmadı.

Kavernomlar en sık (\% 80) serebral hemisferlerde olmak üzere SSS'in herhangi bir alanında görülebilirler $(1,3,5)$. Serebral parankimde en sık subkortikal bölgede ve frontal-temporal loblarda yerleşirler (1). Bizim çalışmamızda da literatürle uyumlu olarak kavernomların $\% 83,4$ 'ü serebral hemisferlerde ve $\% 61,1^{\prime} i$ subkortikal mesafe ile ilişkili alanlarda yerleşim göstermekteydi. Kavernomların 13'ü frontal 6 'sı da temporal loblarda olmak üzere büyük çoğunluğu frontotemporal yerleşimliydi.

Kavernomlar içerdikleri kanama ürünlerinin evresi ve MRG görünüm özelliklerine göre Zabramski tarafından 4 tipe ayrılmışlardır $(3,4)$. MRG'de komplike olmamış kavernomlar trombozis, hemoraji, fibrozis ve kalsifikasyon içerebilen T1 ve T2 de heterojen sinyalli bir çekirdek ve çevresinde T2 ağırlıklı serilerde hipointens hemosiderin halka bulunduran mısır patlağı görünümü verirler (1). Bu görünüm özelliği ise Zabramski Tip 2'yi temsil etmektedir ve kavernomlar en sık olarak Tip 2 paternde karşımıza çıkmaktadır (4). Bizim çalışmamızda da \% 68,1 ile Tip 2 kavernom daha sık saptanmıştır. Kaver- nomu saptamada Gradient T2 ve SWI en duyarlı MRG sekanslarıdır (1). Özellikle SWI sekansının kanama ürünlerine yüksek duyarlılığı nedeniyle bu sekansın yaygın kullanımıyla birlikte özellikle ailesel form ve Tip 4 kavernomların daha sık saptanabileceği düşünülmektedir (2). Aynı zamanda bu sekansın akıma duyarlı olması nedeniyle kavernoma eşlik eden GVA'ların paramanyetik kontrast madde gerektirmeksizin saptanabileceği belirtilmektedir (2). Kavernomlarda yakın zamanda hemoraji gelişmedikçe ya da dev yapıda olmadıkça genellikle kitle etkisi ve perilezyonal ödem içermezler (10). Hemoraji varlığında perilezyonal ödem, kitle etkisi, hemosiderin halkada kayıp, sıvı sıvı seviyelenmeleri gibi atipik görünümler oluşabilir (1). Çaıışmamızda iki kavernom belirsiz sınırlı olarak değerlendirilmiş olup bunlardan biri Zabramski Tip 2 iken diğeri Tip 3 kavernomdu. Akut-subakut kanama ürünü içeren kavernomların (Tip 1) ise $8^{\prime} i$ düzgün konturlu iken $5^{\prime} i$ nispeten düzgün konturlu olarak değerlendirilmiştir. Kavernom tipi ile hemosiderin halkası arasındaki ilişki değerlendirildiğinde Tip 1 kavernomların 6'sında kesintili, 5'inde kesintisiz, Tip 2'lerin 11'inde kesintili, 8'inde kesintisiz halka varken ikisinde saptanmadı. Tip 3 kavernomda ise kesintili hemosiderin halkası saptandı. Çalışmamızda atipik görünüm özelliği olarak bir kavernomda kavernomun içini total olarak dolduran hemorajiye bağlı sıvı sıvı seviyelenmesi saptanırken hemosiderin halkası kesintisizdi. Bu kavernomda hem hemosiderin halkasının olması hem de eşlik eden GVA bulunması kavernom tanısının konulmasında pekiştirici faktörler oldu (Şekil V).

Kavernomların eşlik eden venöz anomali haricinde drenaj venleri olmadığı gibi genellikle besleyici arterleri de yoktur ve ince duvarlı sinüzoidal kanallar içeren dut benzeri morfolojiye sahip yavaş akım paternli vasküler lezyonlardır (10). Yavaş perfüzyonları nedeniyle kavernomların geç kontrastlandığına inanılır ancak kavernomların kontrastlanma dinamikleri ve paternleri değişkendir $(7,10)$. Parasellar bölge kavernomlarına yönelik elde olunan dinamik kontrastlı bir MRG çalışmasında kavernomların \%10'unda kontrastlanma saptanmazken \% 35'inde progresif kontrastlanma saptanmıştır (7). Bu çalışmada kavernomların patolojik alt tiplerinin kontrastlanma dinamiğinde etkili ola- 
bileceği belirtilmektedir (7). Ayrıca geç fazlara doğru progresif kavernom kontrastlanmasının parasellar kordoma ve kondrosarkom gibi homojen kontrastlanan kitlelerden ayrımına katkı sağlayabileceği belirtilmektedir (7). İntraparankimal kavernomların kontrastlanma paternlerini inceleyen başka bir çalışmada ise kavernomların \%42,1'inde kontrastlanma saptanmazken kavernom volümüyle kontrastlanma paterni arasında istatistiki olarak anlamlı ilişki bulunamamıştır (10). Çalışmamızda ise kavernomların \%50'sinde kontrastlanma saptanmadı. Kontrastlanan kavernomlarında \%50'sinde progresif kontrastlanma görülürken kontrastlanan diğer kavernomlarda daha az sıklıkta fokal-punktat, periferal ya da difüz kontrastlanma paternleri görüldü. Çalışmamızda kavernomların patolojik incelemesi yapılamadığından kontrastlanma paterni ile patolojik alt tipi arasında ilişki değerlendirilemezken; kontrastlanmanın kavernom volümüyle istatistiki olarak anlamlı ilişki göstermediği saptandı $(p=0,382)$.

Kavernomların yıllık kanama riski \%0,5-4 civarında tahmin edilmektedir. Evvelce kanayanlarda ve beyin sapında yerleşenlerde, multipl olanlarda bu risk daha yüksektir $(1,3)$. Çalışmamızda BT'de hiperdens kanama ürünü saptanan 13 kavernomlu olgunun MRG'sinde 12'sinin akut-subakut süreçte (Tip 1 kavernom) kanama ürünleri içerdikleri saptanmıştır. Birinde ise MRG, BT tetkikinden yaklaşık 2 ay sonra elde olunduğundan bu kavernom Tip 2 olarak sınıflandırılmıştır. Çalışmamızda akut-subakut süreçte kanama içeren kavernomların büyük çoğunluğu $\left(\% 61,5^{\prime}\right.$ i) kortikal-subkortikal bölgede ve frontal lobda (\%38.4) yerleşim göstermekteyken beyin sapında yerleşmiş olanlarda akut-subakut kanama saptanmadı. Kavernom içerisinde kalsifikasyon olması gradiyent $\mathrm{T} 2$ sekanslarda hipointens görülerek hemosiderin kalıntıları taklit edebilir ya da gradiyent $\mathrm{T} 2$ sekanslarda belirgin hemosiderin kalıntısı içeren kavernomlarda kalsifikasyon ayrımı yapılamaz. Bu tür kavernomlarda BT tetkiki kalsifikasyon varlığının teyit edilmesinde önemli rol oynar. Çalışmamızda tüm hastalara BT tetkiki uygulanmamış olmakla birlikte 6 kavernomda kaba ya da milimetrik-punktat kalsifikasyon saptanmıştır.

Kavernomlu hastalarda klinik, inme, baş ağrısı, kanama ya da lezyonun hacmi ve lokalizasyonu ile ilişkili olarak fokal nörolojik defisitler olarak karşımıza çıkabilir (6). Kavernomlar yaşam boyu inme ve epilepsi riskine de predispozisyon yaratırlar (11). Çalışmamızda da 5'er hasta epileptik nöbet ve inme kliniği ile başvurmuştur. Kavernomlar SSS'de kanama nedeniyle ani ölüme yol açabilseler bile yavaş akımlı vasküler lezyonlar olduklarından genellikle acil medikal tedavi gerektirmezler (6). Cerrahi tedavi hemoraji nedeniyle ciddi nörolojik belirti ve bulguya yol açan ya da yeniden kanayan kavernomlarda düşünülebilir (1) Ancak kavernomla birlikle GVA varlığında GVA'nın drenaj veni oklude olduğunda venöz infarkt riski nedeniyle çoğu beyin cerrahı GVA'nın eşlik ettiği kavernom rezeksiyonundan kaçınır (6). Çalışmamızda da hastalarımızın hiçbirinde cerrahi tedavi uygulanmamış medikal tedavi ve/veya radyolojik takipleri ile izlemleri yapılmıştır.

Kavernomların tedavilerinde konservatif yaklaşım, mikrocerrahi ile total çıkartım veya sterotaksik radyocerrahi yöntemlerinden biri uygulanabilir. Beyin MRG'de insidental, asemptomatik bir kavernom saptandığında konservatif yaklaşım ve yıllık MRG takipleriyle izlem yapılır. İnatçı nöbetler, ilerleyici nörolojik kötüleşme, ilk olarak hassas olmayan beyin bölgelerinde şiddetli kanama ve hassas alanlarda (beyin sapı, motor korteks v.b. alanlar) ikinci defa kanama gibi belirti ve bulgulardan birine yol açan kavernomlarda ise mikrocerrahi ile çıkartım veya sterotaksik radyocerrahi uygulanır. Kavernomlarda girişimsel temel tedavi mikrocerrahi ile total çıkartım iken hassas alanlarda derin yerleşimli, mikrocerrahi riski yüksek lezyonlarda sterotaksik radyocerrahi kavernom progresyonunu önlemek için uygulanabilmektedir (12).

Çalışmamızın retrospektif bir çalışma olması ve kavernom tanılarının sadece radyolojik görünüm özellikleriyle konulmuş olmasının kısıtlılık olduğunu düşünmekteyiz. Pinker ve arkadaşlarının 32 serebral vasküler malformasyonu radyolojik-histopatolojik olarak inceledikleri çalışmalarında kontrastsız MRG'de tipik kavernom görümüne sahip 6 lezyonun histopatolojik analizinde AVM ya da mikst vasküler malformasyon (kavernom+AVM) olduğu saptanmıştır (10). Bu durum sadece kontrastsız MRG özelliklerine 
bakıldığında düşük de olsa diğer vasküler malformasyonların kavernomlarla karışabileceğini göstermektedir. Çalışmamızda lezyonların histopatolojik analizi yapılmadığından kavernomların alt tipleri ile içlerinde mikst vasküler malformasyon olup olmadığı bilinememekte ve bunların MRG görünüm özellikleri ve kontrastlanma paternlerine yansıması tam olarak yapılamamaktadır.

\section{SONUÇ}

Kavernomlar frontotemporal loblarda ve subkortikal alanlarda daha sık yerleşme eğiliminde olan, sıklıkla GVA'nın eşlik ettiği, içerisindeki kanama ürünlerinin miktarı ve evresi ile kalsifikasyon varlığına göre değişken radyolojik görünüm özellikleri sergileyen, volümden bağımsız olmak üzere farklı kontrastlanma paternleri içerebilen vasküler orjinli lezyonlardır.

\section{KAYNAKLAR}

1. Cortés Vela JJ, Concepción Aramendía L, Ballenilla Marco F, Gallego León Jl, González-Spínola San Gil J. Cerebral cavernous malformations: spectrum of neuroradiological findings. Radiologia 2012;54(5):401-9.

2. de Champfleur NM, Langlois C, Ankenbrandt WJ, et al. Magnetic resonance imaging evaluation of cerebral cavernous malformations with susceptibility-weighted imaging. Neurosurgery 2011;68(3):641-7.

3. AG Osborn (Editor). Osborns Brain: imaging, patology, and anatomy. 1st Edition Amirsys: Canada 2013:159-62.

4. Hegde AN, Mohan S, Lim CC. CNS cavernous haemangioma: "popcorn" in the brain and spinal cord. Clin Radiol 2012;67(4):380-8.

5. Smith ER, Scott RM. Cavernous malformations. Neurosurg Clin N Am 2010;21(3):483-90.

6. Petersen TA, Morrison LA, Schrader RM, Hart BL. Familial versus sporadic cavernous malformations: differences in developmental venous anomaly association and lesion phenotype. AJNR Am J Neuroradiol 2010;31(2):377-82.

7. Abla A, Wait SD, Uschold T, Lekovic GP, Spetzler RF. Developmental venous anomaly, cavernous malformation and capillary telangiectasia: spectrum of a single disease. Acta Neurochir 2008;150(5):487-9.

8. Sure U, Butz N, Schlegel J. Endothelial proliferation, neoangiogenesis, and potential de novo generation of cerebrovascular malformations. J Neurosurg. 2001;94(6):972-7.
9. Sohn CH, Kim SP, Kim IM, Lee JH, Lee HK. Characteristic MR imaging findings of cavernous hemangiomas in the cavernous sinus. AJNR Am J Neuroradiol 2003;24(6):1148-51.

10. K. Pinker, Stavrou I, Knosp E, Trattnig S. Are cerebral cavernomas truly nonenhancing lesions and thereby distinguishable from arteriovenous malformations? MRI findings and histopathological correlation. Magnetic Resonance Imaging 2006;24(5):631- 637.

11. Shenkar R, Venkatasubramanian $P N$, Zhao JC, Batjer $H H$, Wyrwicz AM, Awad IA. Advanced magnetic resonance imaging of cerebral cavernous malformations: part I. High-field imaging of excised human lesions. Neurosurgery 2008;63(4):782-9.

12. Mouchtouris N, Chalouhi N, Chitale A, et al. Management of Cerebral Cavernous Malformations: From Diagnosis to Treatment. ScientificWorldJournal 2015;2015:808314. 